other key aspects relating to conservation. Mahe's paper on the subfossils (remains of recently extinct, large terrestrial vertebrates) aptly shows just how much of the fascinating animal life of Madagascar has already been lost for good. Finally, there are two papers on the relationship between man and his environment in Madagascar, one of which (by Brygoo) deals specifically with human disease. In terms of range and content, there is no doubt that this a valuable reference work.

The presentation of the text is, however, poor. It is difficult to understand why the editors went to the trouble of having some of the papers translated into English, whilst others were left in the original French. The resulting mixture falls precisely between two stools. The bulk of the articles have been translated through an agency, with the result that there are numerous errors and distortions which a specialist would have avoided. The text is often turgid and stilted, and one can clearly recognise the original French sentence construction and even most of the vocabulary throughout most of the text. Some papers have no bibliographies; others utilise a variety of systems (numerical, alphabetical etc.). Finally, there are numerous printing errors and stylistic faults (such as inadvertent retention of French figure labels and terminology in some of the translated articles). Overall, the book suffers greatly from inadequate editing; in view of the ambitious price, one might have expected better quality.

R. D. MARTIN

Breeding Birds of Britain and Ireland, by John Parslow. Poyser, Berkhamsted, Herts., £3.60.

Handbook of the Birds of India and Pakistan, Vol. 7, by Salim Ali and S. Dillon Ripley. Oxford University Press, $£ 8$.

Supplement to the Birds of Chile, by A. W. Johnson. D. A. Robb, 3 Muirdown Avenue, London, SW 14, $£ 4.00$.

Birds of Fiji in Colour, painted by W. J. Belcher. Collins, $£ 1.90$.

It is good to have an important new book on British birds to mingle with the many about birds overseas. John Parslow's material is new only in book form, for most of it appeared in British Birds during 1967-68. Here it is brought up to date with a summary chapter of events since 1967, and constitutes the most important survey of the breeding status of British birds since W. B. Alexander and David Lack published theirs in the same journal in 1944. Striking changes have taken place in the past thirty years. One bird, the collared dove, which not one British bird watcher in a thousand had heard of in 1944, has become a widespread and common breeding species. An astonishing number of others have either bred for the first time- snowy owl, firecrest, short-toed treecreeper and bluethroat-or returned after a period of extinction-osprey, avocet, ruff and black-tailed godwit. It was high time, therefore, for the new look, which John Parslow has ably accomplished. One important new feature of the work in its book form is the series of maps, and I was especially glad to see the overly neglected group of introduced species, such as the wood and ruddy ducks, bobwhite quail and three species of pheasant, adequately treated here. It is encouraging, too, that several of the hitherto secret localities can now be revealed, and that we can refer in print to the glories of the Ouse Washes in the Fenland.

I have little to add to what I have already written in Oryx, most recently on page 126 of the last issue, about that magnificent enterprise, the Handbook of the Birds of India and Pakistan. The current volume is the third to be devoted to the great order of song or perching birds, Passeriformes, and carries us from the babblers to the flycatchers, both of which sub-families are extremely well represented in the subcontinent. 


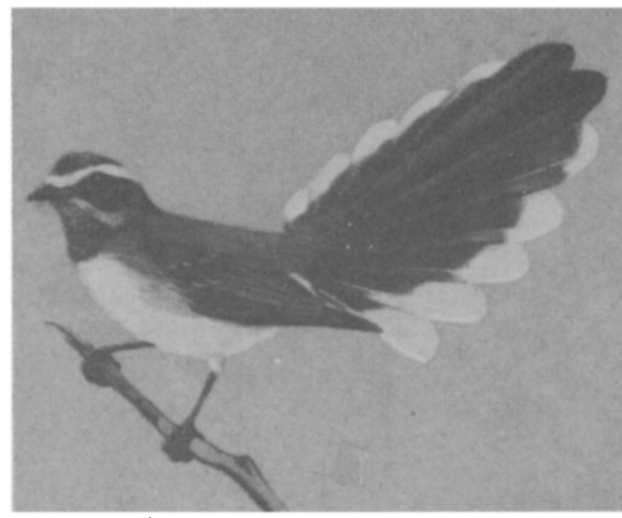

Both text and illustrations continue to be of a very high standard. The artists represented in the current volume are Paul Barruel, C. J. F. Coombs, D. V. Cowen, A. M. Hughes, J. P. Irani, David Reid-Henry, R. A. Richardson, and Robert Scholz. A new feature, of great help to the reader, is the alphabetical list of families, on the end-papers-Latin at the beginning, English at the end - showing in which volume each is to be found.

All owners of A. W. Johnson's Birds of Chile will welcome his supplement, though perhaps with a sad look at the price (nearly $4 \mathrm{p}$ per page), which reflects our current roaring inflation. Like the book the supplement also covers adjacent regions of Argentina, Bolivia and Peru. There are important contributions from J. D. Goodall, W. R. Millie, George Moffett and (on south-west Peru) R. A. Hughes. Twenty hitherto unrecorded species from south-west Peru are included and twenty-two for Chile, the latter including a conebill new to science, Coniristrum tamarugensis, which is illustrated in colour. This was discovered as recently as December 1970 by Dr. Jürgen Rottman. A special visit to Easter Island enabled the avifauna of that remote speck of Chilean territory to be brought up to date.

Mr. Belcher's attractive paintings will appeal even to the millions who will never set foot on Fiji. The excellent notes are contributed by the New Zealand ornithologist, R. B. Sibson.

RICHARD FITTER

\section{Insects of the World, by Walter Linsenmaier, translated by Leigh E. Chadwick, McGraw-Hill, $£ 6.50$.}

This rather unusual book is a popular account of the structural and ecological diversity of insects, of which the author estimates there are more than one million known species. Some recent predictions have suggested that large numbers of species will be lost before they can be even described and named, so enormous is the impact of modern man on natural ecosystems. The outstanding quality and number of the book's illustrations give some idea of what could be lost if such predictions are accurate. The author shows himself aware of the importance of conservation but does not emphasise this rather new aspect of entomology. Photographs, delicate line drawings and striking paintings, all the work of the author, are profusely used to demonstrate the almost unparalleled variety of insect form, colour and pattern. The blended artistic and scientific, although popular, approach is a successful one, particularly of course, in the treatment of such subjects as mimicry and warning coloration.

The text suffers somewhat by comparison with the illustrations. As there is no table of contents, but a plethora of chapter and section headings in different type-faces, the book is difficult and irritating to use, and the short introductory chapters on aspects of entomology such as anatomy, life histories and coloration are uneven, the one on classification being 